\title{
ISLA DE PASCUA Y LA CRISIS ECOLÓGICA EN LA POESÍA DE PABLO NERUDA: RUINAS DE LA IMAGEN INSULAR
}

\author{
ISLA DE PASCUA AND THE ECOLOGICAL CRISIS IN THE POETRY \\ OF PABLO NERUDA: RUINS OF THE INSULAR IMAGE
}

\author{
Marisol Galilea \\ Pontificia Universidad Católica de Valparaíso. Valparaíso, Chile \\ marisolgalilea@gmail.com
}

\begin{abstract}
Resumen: La relación entre el medioambiente y la literatura ha sido el foco de atención de la crítica ecológica o también llamada ecocrítica. Su contribución a los estudios literarios radica en la visibilidad que otorga a la naturaleza y al medio físico en la literatura. En este estudio exploro la significación que adquiere el espacio insular en la producción poética nerudiana sobre Isla de Pascua, proponiendo una lectura en la cual la isla como espacio simbólico se enfrenta a la isla como espacio concreto. Este choque desarma preconcepciones idealizadas encarnadas no solo en el turista que la visita -el propio Pablo Neruda en 1971- sino también en la tradición literaria que ha construido una imagen insular que ya no tiene asidero posible en el mundo sobrepoblado y contaminado actual.
\end{abstract}

Palabras clave: Ecocrítica, imaginarios, turismo, idealización, experiencia.

\begin{abstract}
The relationship between environment and literature has been the focus in ecological criticism, also known as ecocriticism. Its contribution to literary studies stands in the visibility given to nature and the physical world in literature. In this paper I explore the significance of insular space in Pablo Neruda's work about Easter Island. I propose the possibility of reading the island as a symbolic space in confrontation to the island as a concrete reference. This clash dismantles idealized preconceptions incarnated not only in the tourist that visits the place -Pablo Neruda in 1971but also in literary tradition that has built an image of the island with no possible reference in our overpopulated and contaminated actual world.
\end{abstract}

Keywords: Ecocriticism, imaginaries, tourism, idealization, experience.

Recibido: 01.07.2014. Aceptado: 11.03.2015. 


\section{El anhelo insular: Idealización, resguardo y utopía}

Cabemos que sobre las islas descansan símbolos, arquetipos y metáforas. En general, cuando desplegamos nuestra imaginación en torno a una isla, con frecuencia creamos valores positivos. Es por ello que me pregunto qué hace que una isla sea un centro de atracción para el hombre; desde qué tiempos inmemoriales los creadores han recurrido a la isla como foco de sus aventuras y reflexiones; qué es lo que permite que la isla sea más que una realidad geográfica -porción de tierra rodeada de agua por todas partes- una entidad universalmente simbólica, un centro generador de ilusiones y quimeras. En uno de los pocos libros dedicados al tema, Mario Tomé realiza un estudio hermenéutico de la valoración simbólica que la isla ha adquirido en la imaginación literaria, explicando que "desde antiguo, la isla ha sido un continuo objeto de atención humana, revelándose como tema frecuente en el mundo de la mitología y la literatura" (1987: 15). Por su parte, Marcos Martínez ha dedicado su atención a la literatura clásica en relación a los mundos insulares indicando que las islas "son todo menos realidades geográficas" (2010: 140). Su rico simbolismo ha contribuido a una fascinación que se ha dado desde tiempos inmemoriales. Tanto poetas como narradores han "convertido a la isla en el lugar idóneo para el desarrollo de las más insólitas aventuras y fenómenos de todo tipo, dado que una isla viene a ser, con mucha frecuencia, como una especie de centro de atracción en el que convergen innumerables sueños, deseos e ideales humanos (2010: 141). Hay, como bien lo dice Martínez, una "fascinación por las islas" que no resulta fácil explicar, su carga mística y simbólica parece tan natural como compleja de precisar. Las islas son un alter orbis, es decir, otro mundo, espacio privilegiado de lo que Martínez denomina una geografía mental. Su riqueza alegórica hace que sean lugares especialmente idóneos para lo imaginario, donde todo puede suceder, donde todo puede ser posible: lo extraordinario, lo mítico, lo maravilloso; pero también lo terrible, lúgubre y misterioso ${ }^{1}$. A lo anterior hay que agregar la sensación

${ }^{1}$ En su artículo "El imaginario insular antiutópico en la poesía chilena reciente", Oscar Galindo propone un punto de vista contrario al que aquí estoy examinando. El crítico se enfoca en la sensación de encierro que delatan las letras de "los propios poetas insulares. [Quienes representan] las huellas de un discurso que en la poesía 
de distancia, pues "el hecho de que una isla se encuentre situada en medio del océano, se traduce en una percepción de un lugar muy lejano, apartado, fuera del alcance de la mayoría de los mortales". Y es precisamente esta percepción de la distancia, la cual "convirtió a las islas en lugares excepcionales, en los que cabía todo tipo de maravillas, mitos y utopías” (1998: 52). Esta sensación tan propia del ser humano que desea aquello que no puede alcanzar, es lo que explica el especial poder de atracción que desde los inicios de los tiempos ejercen las islas en el hombre. La lejanía ${ }^{2}$ debe ser tomada en consideración a la hora de intentar explicar el porqué las islas ostentan ese lugar de privilegio en el festín de la imaginación humana, pues si lo continental es la norma, lo insular es la excepción. Rodeada de mar hostil, donde reina el peligro a lo desconocido, la isla se ubica como resguardo y protección. Debido a que las islas suelen estar apartadas de lo habitual se constituyen como una noción de difícil acceso, ya que siempre habrá que llegar hasta la isla, alcanzar la isla ${ }^{3}$. Esto caracteriza la mayor parte de la historia del hombre, la cual está presidida por la ignorancia de los límites terrestres, y es en este sentido que la isla se presenta como un espacio geográfico sugestivo y misterioso.

chilena reciente poetiza lo insular en un doble movimiento: islas rurales e islas urbanas. Islas reales e islas imaginarias. Pero sobre todo islas muy poco parecidas al paraíso" (2000: 175-176).

${ }^{2}$ Evidentemente estamos hablando desde el centro (main-land) continental como el locus de enunciación privilegiado en relación a los márgenes (is-lands). En el contexto del Pacífico, Epeli Hau' Ofa profundizó en esta perspectiva que surge desde los centros continentales al imaginar o representar los mundos insulares del Pacífico delineando una distinción entre "islands in the far sea" [islas en el mar lejano] y "our sea of islands" [nuestro mar de islas]. Las primeras son diminutos espacios que flotan a lo lejos, aisladas y misteriosas, mientras que las segundas constituyen el mundo real de quienes habitan estos territorios insulares en constante relación mutua (Hau' Ofa, 1994). Para reflexionar en torno a la representación e imaginación de las islas del Pacífico, también puede ser de interés artículo de Margaret Jolly (2007).

${ }^{3}$ Gabriela Mistral en su Recado sobre las islas escribe "Amor de islas": "Como es condición nuestra que, gustándonos la tierra prefiramos el mar, las costas nos placen, pero las islas son nuestro encantamiento. El mapamundi nos pone los ojos en las masas de los continentes y apenas advertimos la salpicadura de las islas y archipiélagos. Pero son muchas las islas y entre tierras habidas, ellas se nos vuelven las más amadas si a ellas llegamos alguna vez" (2008: 96). Las cursivas son mías para subrayar una característica que se hace constante al intentar definir el magnetismo de las islas que los seres humanos sentimos. "... si llegamos a ellas alguna vez", dice Mistral, es decir, la imposibilidad de la isla se instala como aquello que se anhela en ella. 
Fernando Aínsa, un entusiasta estudioso de la "dimensión representativa de la condición insular" (2001: 17) comenta que una isla, para ser "símbolo y metáfora del ensueño y la memoria, tiene que ser pequeña" (2000: 9), es decir apropiable para las dimensiones sensibles del ser humano. Estas islas pequeñas, no las islas-continente como Australia o islas-nación como Inglaterra o Japón, forman parte de lo que él denomina un "arquetipo del topos insular" (Aínsa, 2001: 18), el cual ha sobrevivido incluso pese a los viajes aéreos que han indiferenciado este espacio, dejando atrás el rito del pasaje marítimo que caracterizaba su ingreso desde la antigüedad. Otro aspecto que contribuye a la idealización de las geografías insulares tiene como principal expresión la sensualidad, feminización y erotización del referente ${ }^{4}$. Las islas han sido fundadas, en el imaginario occidental, por Homero principalmente a través de los viajes de Ulises entre las islas del Mediterráneo. Sus pasos y aventuras por diversas islas fundaron lo que puede llamarse un imaginario insular como un universo cerrado sobre sí mismo, concentrado, como un microcosmos cuyo carácter secreto y replegado representa una condición esencialmente femenina (Aínsa, 2001: 19). La idea de isla-refugio o isla-hogar se desprende de la asociación de la isla con la mujer maternal. Para llegar hasta una isla se debe sortear el obstáculo - para el Behemot, animal de tierra- del mar, y éste es precisamente el símbolo ancestral del origen de la vida. Desde una perspectiva psicoanalítica, atravesar el mar o sumergirse en él es "una regresión hacia el oscuro estado inicial en el líquido amniótico del útero grávido” (Jung, cit. en Tomé, 1987: 65). Así, el tema de la isla funciona como uno de los elementos esenciales del inconsciente: "el regreso ad uterum" (Tomé, 1987: 66). También el espacio curvo, cerrado y regular es por excelencia signo de dulzura, paz, seguridad. El espacio circular es la "imagen del refugio natural, el vientre femenino" (Durand, 2006: 256). Mario Tomé dice que "sin duda, son los poetas quienes más han enriquecido la dimensión erótica de la mujer-isla” (1987: 68). Posesión y penetración serán solo algunos de los rasgos que la sensación erótica evocada por el espacio insular propiciará en el imaginario

${ }^{4}$ Entiendo la feminización como "el traslado de los conjuntos conceptuales definitorios de género de un espacio de conocimiento a otro" (Rodríguez, Ileana. 2002: 86). Las interesantes implicaciones de la feminización de las geografías -en nuestro caso insulares- pueden profundizarse en el artículo aquí citado. 
occidental sobre las islas. De esta forma es posible postular que la figura de la isla permite -en su doble dimensión mujer-maternal y mujer-eróticauna asociación de valoración positiva.

Por otra parte, las imágenes precursoras de lo que llegará a ser la utopía insular se construyen en base a creencias fuertemente arraigadas en la antigüedad, respecto de la existencia de un "más allá" o mundo después de la muerte. Martínez (1999) señala que la expresión griega "makaron nesoi" fue traducida por los latinos como "fortunatorum insulae", desde donde derivaría al español como "Islas Afortunadas" parte de las ideas religiosas sobre la vida en el Otro Mundo. Lo interesante para el crítico es pensar que estas ideas, tan asentadas hoy en día, están originadas en un mito que él ha rastreado y que sería transversal a muchas de las culturas (por no decir a todas) que forman parte de la humanidad. Este mito de las Islas de los Bienaventurados, como una tierra de felicidad - a veces denominada Elíseo o Paraíso- forma parte de una amplia concepción muy extendida, y según la cual "la humanidad ha vivido o vivirá en una situación más dichosa de lo que vive en la actualidad” (Martínez, 1999: 244). Esteban Krotz (2004), desde la antropología, recuerda que ya en las primeras manifestaciones de los pueblos, en sus sistemas de creencias y mitos, es posible detectar esta especial valoración de la isla, la cual se convertirá más tarde en un semillero de utopías. Rafael Pineda Yáñez, en La isla y Colón agrega que todas las islas proyectan una profunda en innegable atracción: "la sugestión encantadora de la paz y la soledad, si están deshabitadas" o bien "la ilusión de su fertilidad y abundancia, si en ellas brota la vida vegetal" o más aún "la idea consoladora del refugio y la seguridad, si el alma se halla conturbada por el terror o simplemente por el peligro acechante de los lugares abiertos e indefensos" (1955: 14). Según Pineda Yáñez, desde la edad paleolítica las islas otorgaron protección ante las amenazas continentales, dejando testimonios de esta "preferencia insular que supone un anhelo de seguridad y acaso el primer indicio de tornar efectiva el ansia de libertad, ante un congruente aislamiento inalterado por contingencias ajenas a uno mismo y más bien por la ingrata vecindad

${ }^{5}$ O también conocidas como "Islas de los Bienaventurados", Islas de los Dichosos", "Islas de los Felices", "Islas de los Dioses" e incluso "Islas de los Muertos", dependiendo de la semántica del adjetivo griego "makários". 
(1955: 15). En este sentido la isla es el espacio que por excelencia permite construir, como en una maqueta, una nueva sociedad en miniatura. $\mathrm{Si}$, como se desprende de la cita anterior, el ser humano sale en busca de la isla para protegerse de "la ingrata vecindad", la isla se sitúa como el inicio de un mudo cerrado y aparte, propicio para una nueva organización social. Habrá así una necesidad de alejarse de lo conocido que se critica para inventar en estos pequeños mundos aislados, sociedad y formas de vida distintas de las habituales. Se conforman, de esta forma, mundos nuevos en base a los sueños e ideales de seres humanos que no se contentan con los límites de lo real o lo posible. Y es así como la estancia en una isla constituye la interrupción necesaria para que la existencia reciba una nueva dirección. En el Diccionario de motivos de la literatura universal, Elizabeth Frenzel indica que las islas son zonas ambivalentes que solo el sentimiento hace unívocas: "si el hombre siente su ambiente, la sociedad, la civilización como carga y amenaza, una isla será para él el refugio deseado; si, por el contrario, se afianza en su forma de vida, no anhelará una isla" (1980: 376).

Este anhelo insular descansa sobre la tradición utópica que ha encontrado en el topos de la isla su mejor metáfora. Como sabemos, los textos utópicos siempre establecen una clara relación con su respectiva realidad sociocultural, la cual es compartida y reconocida por sus lectores ${ }^{6}$. Y, a pesar de que los narradores de estos textos utópicos no logran informar sobre la ubicación precisa de estas islas de ventura, nunca se trata de un país cualquiera de cuentos de hadas7. Es así como la idea de Frenzel respecto de la isla en su "función de contrapunto frente a la existencia normal" se construye en base a los textos clásicos fundadores de lo que hoy conocemos como las Utopías del Renacimiento de Moro, Campanella y Bacon, situados precisamente en islas y en constante diálogo con sus propios contextos ${ }^{8}$. La

${ }^{6}$ Jameson llama a esto el subtexto del texto utópico, el cual funciona como un "otro" en su estructura: "the basic relationship of the Utopian text to what we been calling its referential sub-tex is one of neutralization; or in terms of More's Utopia, that the island of that name functions as a point-by-point negation or canceling of the historical England itself" (1977: 9).

${ }^{7}$ Esto sucede porque el narrador deja expreso que él ha visitado ese lugar, y también deja explícito que ese es un lugar posible. Para profundizar en este punto se puede consultar Krotz, 2004: 240.

${ }^{8}$ Para un profundo y completo análisis de la estructura lingüística del discurso utópico, ver Alonso, Blum, Cerda, Cid, Oelker, Sánchez, Triviños y Villavicencio (2005), específicamente pp. 37-44, donde se refiere al caso de Utopía de Moro. 
imagen idealizada que en general es construida por los sujetos occidentales-continentales cuando piensan en el espacio insular debe conectarse -también-con "el marco en el que se mueven los imaginarios del conquistador [los cuales] comienzan con [...] la condición 'paradisíaca' que se le atribuye a las Indias a partir de los viajes de Colón” (Pizarro, 2009: 34). Esta asociación con el paraíso desarrolla motivos edénicos en los escritos de navegantes que llegaron a la Terra Incognita y se funda no tanto en la adquisición de nuevas nociones, sino en la verificación de antiguas leyendas como "las profecías del Antiguo Testamento, los mitos grecolatinos como La Atlántida y Las Amazonas [o] las leyendas medievales" (Lévi Strauss. Cit. en Magadish y de Beer, 2001: 45). Esta búsqueda de verificación como motivación de los viajes de exploración adquiere un sentido especial en lo que más adelante profundizaré. Ya que -sostengo- la idealización del espacio insular que se puede demostrar en el poemario de Pablo Neruda $L a$ rosa separada está fuertemente adherida a un imaginario paradisíaco de las islas, el cual, al igual que los mitos y leyendas de la cita anterior, busca una comprobación empírica. De esta forma, el anhelo de verificación permite conectar y hacer asociaciones entre los descubridores de los siglos XV y XVI y Neruda ${ }^{9}$. Jaime Concha analiza las connotaciones post-residenciarias del verbo "cruzar", las cuales bifurcan los valores del término produciendo una significación histórica y una significación de horizonte utópico. La primera se encuentra principalmente en Canto general y la segunda está en las obras terminales de $\mathrm{Neruda}^{10}$, a partir de los años 60:

Amenaza de la conquista y umbral cosmogónico; invasión y utopía conjugan una dialéctica que se irá disolviendo, en los últimos días, en una poderosa reactualización de un gran espejismo que recorre el Pacífico Sur desde mapas del siglo XVI hasta Pougainville y Cook: la búsqueda

${ }^{9}$ Para profundizar en estas conexiones entre los diarios de los primeros navegantes que llegaron a Isla de Pascua y la poesía de Neruda se puede consultar Galilea (2013) y también Galilea, 2015: 94-99.

${ }^{10}$ Me interesa remarcar que La rosa separada ha sido mayormente foco de interés para la crítica en el universo de la poesía última y póstuma de Neruda. Un especialista en este corpus es Osvaldo Rodríguez, quien ha conectado la poesía póstuma con el motivo del viaje $(1995,2004,2012)$. Sin embargo, pocos son los estudios que se interesan por analizar estos libros de manera autónoma. Entre estos destaco la tesis y artículo de Brenda Müller (2011). 
de la Terra Incognita Australis, centelleante todavía en La rosa separada (1973). Es como si, antes de su noche, Neruda vislumbrara la posibilidad de un descubrimiento sin exterminio, de una navegación pura sobre aguas puras del océano, el hallazgo de tierras que fueran sola, única y exclusivamente -más allá de toda prehistoria- un Mundo Nuevo (Concha, 1985: 117).

Pienso que estas palabras de Jaime Concha permiten introducir el referente geográfico de La rosa separada que menciona en la cita, es decir, la Isla (Isla de Pascua) como esa Terra Incognita Australis, ajena al exterminio propio de los descubrimientos, y el soñado hallazgo de un Mundo Nuevo. El horizonte utópico está tras esta búsqueda y subyace en éste la imagen insular arquetípica como anhelo de felicidad. Estos dos elementos contribuyen a la imagen orientalista que de Isla de Pascua se forma Neruda, y que más adelante analizaré. A partir de lo expuesto hasta ahora me interesa conectar esta valoración positiva que la insularidad ha representado en la imaginación poética de Pablo Neruda, pues, tal y como dice el profesor Luis Sáinz de Medrano: "un poeta tan obsesionado por la aproximación a la naturaleza como Pablo Neruda había forzosamente de encontrarse con las islas, espacios cuya carga mítica no es necesario ponderar" (2001: 565). A continuación exploraré la imagen de la isla como un más allá lejano, distante y misterioso que se distingue cuando el poeta escribe sobre -o a partir de- Isla de Pascua ${ }^{11}$.

\footnotetext{
${ }^{11}$ El estudio que ofreceré pretende contribuir a las lecturas ecocríticas que están siendo desarrolladas en Chile en particular por Mauricio Ostria (2002, 2004 y 2010) y Juan Gabriel Araya (2006), principalmente gracias a la adjudicación del Proyecto Fondecyt $\mathrm{N}^{\mathrm{O}} 1080338$ "Lecturas ecocríticas de textos literarios contemporáneos". Entre los autores estudiados se destacan Huidobro, Mistral, Oses, Coloane y, por supuesto, Neruda. En el medio español es Niall Binns quien mayormente se ha encargado de estudiar la poesía hispanoamericana desde la perspectiva ecológica. Por su parte, Steven White (2006) resalta en el medio anglosajón por su visibilización de la poesía de nuestra región realizando interesantes lecturas ecocríticas. Los dos últimos recogen a Neruda dentro de un grupo mayor, deteniéndose en su producción solo en la medida en que sea comparable con otros autores latinoamericanos que se han preocupado por la naturaleza. Ostria y Araya destacan como referentes de la "ecocrítica nerudiana”, si es que puede así llamársele a los pocos estudios que actualmente existen.
} 


\section{"Hacia tan lejos": Isla de Pascua en la imaginación poética nerudiana}

El año 1971 fue importante para Neruda, pues es nombrado embajador en Francia por el gobierno del recién electo Salvador Allende; además de ser reconocido a fines de octubre de ese año con el Premio Nobel de Literatura. Antes de partir a París viaja a Isla de Pascua con motivo de la filmación del documental "Historia y geografía de Pablo Neruda", el cual fue proyectado para ser transmitido en diferentes capítulos para Canal 13 de la televisión chilena. Cuenta su productor Hugo Arévalo ${ }^{12}$ que fue el propio Neruda quien insistió en sumar Isla de Pascua a las otras geografías chilenas inicialmente proyectadas en el rodaje del documental de veinte capítulos, y cuya sección número trece, de veinte minutos de duración, está filmada íntegramente en Rapa $\mathrm{Nui}^{13}$. En lo que sigue examinaré un poema que permite abrir la puerta del imaginario insular y las meditaciones que en particular Isla de Pascua despliega en la poesía de Pablo Neruda.

"Hacia tan lejos" e "Introducción en mi tema" corresponden a un mismo poema que con sutiles diferencias fue publicado en Geografía infructuosa y en La rosa separada respectivamente ${ }^{14}$. Hernán Loyola, en las notas al tomo III de las Obras Completas, indica:

A comienzos de 1971 viajó (por primera vez) ${ }^{15}$ a la Isla de Pascua con un equipo de camarógrafos y técnicos del Canal 13 de la TV chilena para

${ }^{12}$ En entrevista personal. Isla Negra, agosto 2009.

13 "Rapa Nui: declaración solemne" es el título de la prosa poética que Neruda lee ante las cámaras durante su visita a Isla de Pascua en 1971. Es posible encontrar el texto en las Obras Completas editadas por Hernán Loyola, "Nerudiana dispersa II" (2002: 320-321), gracias a la transcripción desde la columna sonora del filme por su productor, Hugo Arévalo. Además aparecen otros dos textos, también inéditos, que forman parte del Documental "Historia y geografía de Pablo Neruda". Uno referido al capítulo dos, "Una casa en la arena" y el otro al capítulo cuatro "Nacieron los veinte poemas". Para un análisis de "Rapa Nui: declaración solemne" se puede consultar mi tesis (2013: 232-244), en la cual analizo la "performance" de Neruda en Rapa Nui.

${ }^{14}$ Las divergencias que hay entre ellos - partiendo desde el título- ya han sido anotadas por Osvaldo Rodríguez (1986), Charles Marcilly (1976) y Eliana Rivero (1976), sin embargo, es Mario Rojas (1981) quien mayor detalle ha ofrecido de ambos poemas a partir de un meticuloso análisis intertextual interpretado desde su estrato mítico.

${ }^{15}$ Para ahondar en el tema del viaje -imaginario o real- que realizó Neruda a Isla de Pascua, se puede consultar Galilea (2013: 8-15), donde comento las posturas del 
filmar allí unas escenas del documental Historia y geografía de Pablo Neruda, con libreto de María Maluenda. Regresó con el poema "Hacia tan lejos", recogido en GIF [Geografía infructuosa], y con un libro que publicará en Francia: La rosa separada (2002: 993-94).

Si bien mi intención aquí no es realizar la labor detectivesca de averiguar dónde fue escrito el poema, pienso que no es factible aseverar que "Hacia tan lejos" haya sido escrito tras la visita de Neruda a Isla de Pascua, ya que si así fuere ¿̇por qué incluirlo en Geografía infructuosa y por qué otorgarle el estatus de prólogo o de "Introducción en mi tema" -con sutiles diferencias- en La rosa separada? Por el contrario, mi hipótesis propone que este poema debe haberse escrito justo antes de partir, antes incluso de llegar al aeropuerto y subirse al avión. El imaginario insular nerudiano, así como la experiencia del sujeto en la isla como un turista más, contribuirá a explorar la significación que adquiere este poema en cada uno de los libros donde fue incorporado. El tono es muy diferente al resto de los poemas de La rosa separada. En "Hacia tan lejos", como en "Introducción en mi tema" hay optimismo, hay claridad ante la razón del viaje -"Viajé a recuperarlas [a las estatuas], a erigirlas en mi domicilio desaparecido"-, hay esperanza -"recomienzo las vidas de mi vida"-. Sostengo que todo lo anterior se confunde y cambia desde el momento en que Neruda se sube al avión con el resto de los viajeros turistas. Uno de los rasgos (y el más evidente) que llama la atención es el cambio de título que reciben los poemas en los libros donde se inscriben. "Hacia tan lejos" implica -como lo veíamos más arriba - una añoranza por una geografía que hay que alcanzar, a la cual hay que llegar, probablemente sorteando innumerables obstáculos, aquella lontananza puede convertirse en la preciada meta de un sujeto atado a sus circunstancias continentales ${ }^{16}$. "Hacia tan lejos" es una esperanza vital en

estudioso español Gunter Castanedo, quien propone que Neruda habría estado en 1945 en la isla por motivos amorosos; y la de Darío Oses (1999), el cual postula que aquel viaje fue solo con su imaginación poética.

${ }^{16}$ Estas circunstancias pueden conectarse -si atendemos a la tentación de la lectura biografista que ronda a la crítica nerudiana- con aspectos del plano personal del poeta en 1971. Para los detalles de estas circunstancias se puede revisar la biografía de Teitelboim (1984: 362-363) y también el Epílogo "Y para qué vinimos a la isla?" (Galilea, 2011: 108-109) que escribí para la traducción de La rosa separada al rapa nui. 
medio de lo infructuoso de su geografía existencial ${ }^{17}$. El sujeto -alter ego de Neruda- le escribe a la Isla de Pascua, hacia donde sale a recomenzar su vida; su escritura asume la tradición del espacio insular donde el proyecto político se conjuga con la esperanza. A pesar de que Loyola indica que “...los poemas chilenos del libro [se refiere a Geografía infructuosa] no evidenciaron huellas de los ajetreos políticos de 1969 (segunda mitad) y 1970 (primera mitad)" (2002: 993), yo sostengo que "Hacia tan lejos" puede leerse como un viaje hacia un alter orbis insular. Esto es, un espacio privilegiado de una geografía mental donde la riqueza alegórica de la isla permite que ésta sea un lugar especialmente idóneo para lo imaginario, donde todo puede suceder, donde todo puede ser posible. Ahora bien, "Introducción en mi tema" deja de lado el título que hemos sopesado como esperanzador para el sujeto en el contexto de Geografía infructuosa, dando señas de que la función que el poema cumplirá en La rosa separada, una introducción al tema, debe leerse con algún grado de sospecha. Otro aspecto que llama la atención y que conecta el topos insular con la imaginación utópica está dado en la primera estrofa del poema18: "A la Isla de Pascua y sus presencias/ salgo, saciado de puertas y calles,/ a buscar algo que allí no perdí”. Se subraya en este verso el espacio cerrado, casi claustrofóbico, sinecdóticamente connotado de la ciudad. El sujeto "sale" hacia Isla de Pascua "saciado de puertas y calles", cansado del ambiente cerrado y hostil de la urbe. A esta negativa apreciación se suma el adjetivo "seco" que aparece en la siguiente estrofa ${ }^{19}$ : "El mes de enero, seco,/ se parece a una espiga:/ cuelga de Chile su luz amarilla/ hasta que el mar lo borra/ y yo salgo otra vez, a regresar". El pavimento y su encierro se potencian por la época del año en la cual se observa la ciudad: el mes de enero. El contraste es evidente, el mar es quien borra aquel espectáculo cerrado e inhóspito. Es

\footnotetext{
${ }^{17}$ Oscar Hahn reflexiona en torno a lo infructuoso de ciertas circunstancias biográficas de Neruda que podrían explicar la figura de la hipálage que a su juicio dibuja el título de Geografía infructuosa (2004: 7-10).

${ }^{18}$ Las diferencias entre las versiones de "Hacia tan lejos" e "Introducción en mi tema" tales como la incorporación de una coma en el verso dos o el cambio del posesivo "sus" por el artículo "las" del verso uno las examina Rojas en el artículo anteriormente citado. Las cursivas son del poema original.

${ }^{19}$ Rojas nota cómo la coma añadida -en la versión de "Introducción en mi tema"al final del verso cuatro aísla el término reforzando su valor semántico y multiplicando así la connotación negativa del espacio que se deja atrás: la ciudad encerrada y seca.
} 
el océano y su gran masa de agua quien otorga la lejanía necesaria para borrar el Chile seco y urbano que aqueja al sujeto. Se crea, de esta forma, una distancia entre la ciudad en verano -mes de enero- y su esterilidad -secaque el viaje pretende olvidar o al menos cambiar por su contrario: esto es, ya no una ciudad -puertas y calles- sino que ahora un espacio abierto: " $Y$ aquí rodeado de presencias grises,/ de blancura espacial, de movimiento/ azul, agua marina, nubes, piedra,/ recomienzo las vidas de mi vida". Se conforma una estructura basada en la oposición ciudad/isla o bien ciudad/ lejanía con toda la connotación negativa al primero de los opuestos y toda la valoración positiva para el viaje que se emprende como una necesidad urgente que paradójicamente se expresa como: "a buscar algo que allí no perd $\imath^{\prime 20}$. Isla de Pascua aparece como el lugar propicio para recomenzar "las vidas de mi vida". La esperanza por encontrar aquel espacio abierto que los colores y los elementos refuerzan -blancura espacial, agua marina, movimiento azul, nubes, piedra- impulsan al sujeto a acercarse a la isla provisto de todo un engranaje de supuestos que la tradición le brinda. Imágenes prístinas donde el acto de recomenzar la vida está íntimamente conectado con el paisaje virgen y casi mítico.

La desconfianza que provoca el cambio de título "Hacia tan lejos" por "Introducción en mi tema" puede entenderse si examinamos la temática del regreso que está conectada con esta idea del recomenzar la vida en la isla. Eliana Rivero apunta una interesante reflexión respecto a la significación que supone este tema en La rosa separada, pues en este libro el regreso adquiere "una delimitación espacial y conceptual como dentro de un marco compuesto por el motivo final en radical oposición al inicial” (1976: 470). Si en esta Introducción al tema hay un verso que dice " $y$ yo salgo otra vez, a regresar", en el poema final del libro ("La isla XXIV") el sujeto se despide de la isla para levar anclas y partir de vuelta a la ciudad: "Adiós, adiós, isla secreta [...]/ volvemos unos y otros a las obligaciones [...]/ Regresamos". Esta contradicción en términos direccionales es analizada por Rivero desde su enunciación, pues el "nosotros regresaremos" (de la Isla al continente-

\footnotetext{
${ }^{20}$ Para Osvaldo Rodríguez (1986: 514-15) en La rosa separada, la noción de "pérdida" es un núcleo semántico que explica el impulso de búsqueda con que el hablante asume el viaje a la Isla, ya que no solo proyecta el viaje debido al cansancio de las "puertas y calles", sino que también hay una indeterminación respecto de "algo" que en la Isla se desea encontrar.
} 
ciudad) al mundo establecido, comercializado, históricamente progresivo y progresista es diferente del "yo regreso" (del continente-ciudad a la Isla) al espacio sin límites, sin tiempo, al origen que se veía en "Introducción en mi tema”. La perspectiva colectiva da un significado opuesto al "regreso", y en este sentido concuerdo con Rivero en que ya no es un "retorno a la pureza primigenia, sino la vuelta al necesario oficio de vivir diariamente" (1976: 470). Ahora bien, la desconfianza que despierta el título "Introducción en mi tema" tiene que ver precisamente con este regreso esperanzador que describe el sujeto en el primer poema de La rosa separada. Poema que no se ubica en ninguna de las dos subseries que conforman el libro -Los hombres y La isla- sino que se posiciona como una especie de prólogo irónico. En cambio, "Hacia tan lejos" aparece en Geografía infructuosa sin otros poemas en relación a Isla de Pascua con los cuales sopesarlo. Es un poema en medio de otras meditaciones, pudiendo fácilmente intercambiarse Isla de Pascua por cualquier otro espacio que en el imaginario común despliegue asociaciones de pureza, lejanía y lontananza. En este libro, el poema "Hacia tan lejos" navega solo, sin otros textos "insulares" a los cuales oponerlo. O dicho con otras palabras, el poema no presenta mayores conflictos en su lectura debido a que ocurre un regreso lineal: el hablante regresa a Isla de Pascua en busca de un "recomienzo las vidas de mi vida". Sin embargo, "Introducción en mi tema" presenta un problema con la lectura lineal que proponíamos para "Hacia tan lejos", pues, me pregunto ċpor qué el hablante comienza con un regreso desde la ciudad hacia la Isla y termina con un regreso contrario? Estos regresos opuestos me hacen sospechar que uno de ellos no cumple la función que dice que cumple, esto es, regresar, sino que se aleja de ella. Interesa, por tanto, examinar por qué esta discordancia entre ambos regresos que presenta La rosa separada, y con ello marcar la función irónica que el regreso inicial (de la ciudad hacia la isla, presente en "Introducción en mi tema") representa en el enunciado mayor del libro y, a partir de lo anterior, descubrir la función analógica que cumple el poema "Hacia tan lejos" en Geografía infructuosa.

\section{La Isla: Herencia de una imagen literaria agotada}

En base a las categorías analogía e ironía que Octavio Paz (2008) propone 
en Los hijos del limo, pienso que "Introducción en mi tema" cumple una función irónica en el contexto de La rosa separada; y que por el contrario "Hacia tan lejos" se acerca más a un papel analógico en el marco de Geografía infructuosa. El crítico mexicano explica que la poesía moderna puede entenderse como una reacción frente, hacia y contra la modernidad, pero que al disputar con el racionalismo moderno, los poetas descubren una tradición que Paz entiende como la categoría estética de la analogía. Esta visualiza el universo como un sistema de correspondencias en el cual el lenguaje se entiende como doble del universo. Sin embargo, esta categoría está carcomida por una conciencia de la modernidad fundada en la contradicción que muestra la disociación de lo que parecía uno, la escisión de lo idéntico, el otro lado de la razón, el quiebre del principio de identidad, es decir, la categoría estética de la ironía. Para Paz, el tema de la poesía moderna corresponde, por un lado, a un diálogo contradictorio con y contra las revoluciones modernas y las religiones cristianas, y por otro, en el interior de la poesía y de cada obra poética es también un diálogo entre analogía e ironía. "Si la analogía hace del universo un poema, un texto hecho de oposiciones que se resuelven en consonancias, también hace del poema un doble del universo", pero hay un momento en que la correspondencia se rompe creando una disonancia que en el poema se llama ironía y en la vida se denomina mortalidad: "La poesía moderna es la conciencia de esa disonancia dentro de la analogía" (Paz, 2008: 64). Según el crítico, la analogía es una manera de volver habitable el mundo, pues a la contingencia y al accidente, opone la regularidad; y a la diferencia y a la excepción, opone la semejanza. La historia de la poesía moderna, desde el romanticismo hasta fines del siglo XX, es inseparable de esta corriente de ideas y creencias inspiradas por la analogía: "La analogía es el reino de la palabra 'como', ese puente verbal que, sin suprimirlas, reconcilia las diferencias y las oposiciones" (Paz, 2008: 74). Por el contrario, la ironía -al igual que la muerteanula las reglas y las leyes que construye la analogía, creando una estética de lo grotesco que niega la legibilidad del mundo basándose en la ruptura de la unidad: "La ironía es la herida por la que se desangra la analogía, es la excepción, el accidente fatal, [...] lo necesario y lo infausto" (Paz, 2008: 81). Nial Binns retoma los conceptos de analogía e ironía propuestos por Paz y los aplica en un análisis ecocrítico que realiza de la poesía de José Emilio Pacheco explicando que: "el mundo ha cambiado lo estamos destruyendo 
y al ritmo de la destrucción cambian también, la visión y la poesía de este mundo" (2001: 141). Para él, las "analogías comienzan a hacer agua y la confianza en lo inmutable se quiebra” creando a través de la yuxtaposición entre pasado y presente un contraste que permite resaltar "el horror de lo que está ocurriendo [...] los efectos disonantes de la modernización” (2001: 141). Binns resalta la insustentabilidad de los recursos poéticos tradicionales, los cuales al ser utilizados en contextos actuales pasan a cumplir un papel irónico a través del cual se evidencia el trágico desgaste de ciertos aspectos temáticos y estructurales de la poesía.

Desde esta perspectiva, creo que el espacio insular como símbolo y tradición literaria que hemos revisado al comienzo de este trabajo bien puede entenderse como un recurso poético gastado que debe repensarse cuando aparece hoy en día en la poesía contemporánea. Insisto además en que no es irrelevante el comentario que apunté más arriba, en el cual cuestioné la aseveración de Hernán Loyola cuando explicaba que Neruda habría escrito "Hacia tan lejos" tras el viaje a Isla de Pascua. Pienso, por el contrario, que el hecho de haber conocido la Isla, de haberla recorrido, de vivir la experiencia del viaje en aquel enero de 1971 - “espacio de experiencia”- a Rapa Nui marca en esta poesía un contraste entre lo que la Isla representaba para el poeta -"horizonte de expectativa"- y lo que ella representa en el mundo actual ${ }^{21}$. Binns lo explica claramente en su estudio sobre la poesía de José Emilio Pacheco. Citando el poema "Orquídeas" analiza cómo "la demanda insaciable del capitalismo" transforma "lo salvaje, lo vivo,/ lo perdurable por efímero" en algo muerto como ornamento para una "sala elegante" (2001: 137). Al igual que estas orquídeas, la Isla ha sido demandada por el "insaciable capitalismo" que la requiere para el usufructo que la empresa turística pueda darle a este lugar. La única "utilidad” que Isla

${ }^{21}$ Tomo estos términos "espacio de experiencia" y "horizonte de expectativa" de Reinhart Koselleck (1993) quien propone que en el mundo de progreso y tecnología actual el horizonte de expectativas se vio potenciado pensando que siempre sería posible alcanzar más y mejores condiciones de vida. Sin embargo, el espacio de la experiencia dio lentamente cuenta de que aquellas expectativas no podrían ser correspondidas con la realidad. Este distanciamiento, este choque abrupto, entre expectativa y experiencia es lo que para el autor define al mundo contemporáneo y que utilizo aquí para indagar cómo se manifiesta esta oscilación en la poesía de Neruda y la expectativa/experiencia de Isla de Pascua. 
de Pascua representa para Chile en este mundo actual es la divisa en dólares que dejan sus esporádicos visitantes ${ }^{22}$. Este es el mensaje que recibe Neruda tras permanecer quince días en Isla de Pascua, esta es la empírica comprobación de que ya no existe el referente que su sensibilidad de poeta le invitaba a imaginar y buscar. Esa imagen utópica del espacio insular como resguardo o bien como el recomienzo de "las vidas de mi vida" se ve truncado ante el espectáculo de un espacio atiborrado de turistas, de "torpes transeúntes" ("Los hombres IV") que solo "juntando plata" ("Los hombres II") han llegado hasta la isla. La personificación del hablante a través de la categoría de turista ${ }^{23}$ está negativamente representada a través de las páginas de La rosa separada, abriendo paso a la constatación de que Isla de Pascua ya no es aquel paraíso alejado de soledad y renovación. Ya que, ante la evidencia de la experiencia, el espacio colapsado e invadido de turistas que poco interés tienen en el paisaje que los rodea revela un imaginario anacrónico que no se condice con el espectáculo de degradación que se presenta: "aquí estoy, como los otros pesados peregrinos/ que en inglés amamantan y levantan las ruinas:/ egregios comensales del turismo, iguales a Simbad/ y a Cristóbal, sin más descubrimiento/ que la cuenta del bar" (“Los hombres I"). Es más, estos "pesados peregrinos" llegan a la Isla en el medio de transporte aéreo moderno por antonomasia: "Me confieso: matamos/ los veleros de cinco palos y carne agusanada,/ matamos los libros

${ }^{22}$ La historia de Isla de Pascua puede explicarse como una seguidilla de actos de explotación y colonización que daban "utilidad" a este remoto espacio. Desde que fue "descubierta" al mundo occidental, la Isla ha sido un espacio fértil para múltiples representaciones exotizantes y también para actos de dominación explícitos. Entre ellos está la extracción de su población para ser utilizados como esclavos y su posterior merma debido a enfermedades tales como la lepra; o bien la apropiación del espacio para la cría de ganado ovino relegando a los habitantes originarios a reales ghettos de pobreza (para conocer esta perspectiva puede consultarse Fisher, 2001). Pienso que desde fines del siglo XX, Isla de Pascua ha cambiado su "utilidad" y ahora ha pasado a convertirse en un destino de turismo cultural. Para algunos autores, el turismo es una nueva forma de dominación que los países desarrollados han inventado para mantener el subdesarrollo de sus ex colonias. Véase Noel Salazar (2006), Gabriela Nouzeilles (2004) y Forrest Young (2012).

${ }^{23}$ José Varela (1992) realiza un recorrido por la historia para entender cómo se ha llegado a lo que hoy en día concebimos como turismo. Analiza al turista -y junto con él al sujeto de La rosa separada- como un personaje representante de la clase media que busca paisajes escapistas para arrancar de la ciudad alienante. Para una discusión en torno al turismo y su relación con la naturaleza puede consultarse Galilea, 2013: 128-136. 
pálidos de marinos menguantes,/ nos trasladamos en gansos inmensos de aluminio,/ correctamente sentados, bebiendo copas ácidas,/ descendiendo en hileras de estómagos amables" ("Los hombres I"). En el imaginario insular que al comienzo del trabajo comenté, no hay cabida para un jet privado que permita alcanzar la isla. Esta es el premio ansiado tras el viaje de aventuras, la añorada meta tras los avatares del camino. El avión, por tanto, rompe este esquema provocando lo que Delgado (2000: 246) denomina "el efecto túnel", el cual borra las distancias y junto a ellas el premio que la llegada al paraíso insular significaban en la tradición. Por lo tanto, concuerdo con Binns en que "desde una perspectiva realista, ya no se puede idealizar un lago contaminado; desde la lucidez de la poesía, ya no se puede seguir empleando un lenguaje y una imaginería anacrónicos. El péndulo de la poesía moderna, que iba y venía para Octavio Paz entre la analogía y la ironía, vira definitivamente hacia ésta" (2001: 158). El lago contaminado, al igual que las orquídeas que comentábamos en la cita más arriba, son homologables al espacio geográfico insular. Isla de Pascua es el lugar más alejado de cualquier otro punto terrestre habitado del globo y, por tanto, se presta a la imaginación como un refugio ante los embates de una incontrolable modernidad que se erige como amenaza para la sensibilidad de un poeta en estrecho vínculo con sus raíces telúricas del sur de Chile. En este sentido, es interesante preguntarse por la imaginería que despierta la isla como espacio de condensación simbólica en la literatura para poder, de esta forma, examinar -tal y como Binns lo propone- "las connotaciones simbólicas, supuestamente perennes, [que] han entrado en crisis" (2001: 150).

Es así como en el poema de Geografía infructuosa que hemos comentado, esto se subraya a partir del propio título "Hacia tan lejos", esto es un anhelo de distancia frente a rutinas agobiantes propias de la vida en la urbe que se desea dejar atrás al menos por un breve lapso. Y veíamos cómo el poema se construye en base a la oposición con una ciudad que encierra y atrapa frente a un espacio insular que se presenta como amplio, abierto y en refrescante movimiento. "Hacia tan lejos" es un poema de esperanza que se construye en base al estereotipo de la isla que la tradición ha conservado, esto es, un lugar lejano, paradisíaco, ajeno a los embates de la modernidad y propicio al reencuentro del ser consigo mismo. Por el contrario, ya desde el propio título - "Introducción en mi tema"- es posible desconfiar o al menos sospechar del poema. Esta introducción se distancia del conte- 
nido de La rosa separada, tanto en su forma como en su contenido. En su aspecto formal no toma posición frente a la dicotomía de sus títulos -Los hombres / La isla- y en su contenido se ve enfrentado con la esperanza que el verso final "recomienzo las vidas de mi vida" significa frente a la atmósfera de desencanto y frustración de la mayor parte de los 24 fragmentos que componen el poemario. Por lo tanto, pienso que el descriptivo título de "Introducción en mi tema" debe entenderse como el agotamiento de la herencia que el símbolo insular representó hasta antes del efectivo viaje a la isla más alejada del planeta que realiza Neruda en 1971. La visión tradicional literaria que presentaba a la isla como centro de fuerza, de atracción y fascinación ha entrado en crisis para el poeta que efectivamente evidencia la decadencia del otrora paraíso terrenal subrayado por una tradición que se encargó de estereotipar, fijar e inmovilizar un espacio que al igual que el resto de las geografías, ha sido acaparado por intereses económicos que rigen nuestra vida moderna. Es por esta razón que el poema "La isla XXIII" que cito a continuación, representa un punto de diálogo frente a esta función irónica que cumple "Introducción en mi tema": "Porque si coincidiéramos allí/ como los elefantes moribundos/ dispuestos al oxígeno total,/ si armados los satisfechos y los hambrientos, / los árabes y los bretones, los de Tehuantepec/ y los de Hamburgo, los duros de Chicago y los senegaleses,/ todos, si comprendiéramos que allí guardan las llaves/ de la respiración, del equilibrio [...]/ si navegáramos en tropel hacia la Isla,/ si todos fueran sabios de golpe y acudiéramos/ a Rapa Nui, la mataríamos, / la mataríamos con inmensas pisadas, con dialectos,/ escupos, batallas, religiones,/ y allí también se acabaría el aire". Los versos aquí transcritos dan cuenta de una situación hipotética que el hablante configura para explicar que deben ellos, nosotros, los turistas- abandonar la Isla. Lo interesante es el uso del condicional que supone un futuro catastrófico para este lugar, ya que a lo largo del libro ese futuro ha sido manejado a modo de profecía autocumplida, pues la Isla ya ha sido destruida por la invasión de turistas que a ella ha arribado. Esta elección modal en la conjugación de los verbos de "La isla XXIII" se asocia a la esperanza que "Hacia tan lejos" y su ánimo de dejar atrás la ciudad para encontrarse con el espacio prístino que le prometía la Isla significan. Sin embargo, esta asociación corresponde a una asociación irónica, pues si en "Hacia tan lejos" se añoraba el espacio alternativo de la isla como promesa de recomenzar, en "La isla XXIII" ese futuro implica ya 
la muerte que se vaticina especialmente en los versos: "si navegáramos en tropel hacia la Isla,/ si todos fueran sabios de golpe y acudiéramos/ a Rapa Nui, la mataríamos”. Sin embargo, la Isla ya está muerta, ya fue asesinada. Esto se corrobora con los últimos tres versos del poema: "caerían al suelo las estatuas,/ se harían palos sucios las narices de piedra/ y todo moriría amargamente" ("La isla XXIII"). Las estatuas ya han caído al suelo, ya se ha navegado en tropel hacia la isla, ya se ha invadido con escupos, religiones, pisadas y dialectos. El futuro que preocupa al hablante ya ha sucedido y por eso pienso que la función que tiene la elección de esta modalidad verbal está en diálogo con el cambio realizado en los verbos "salir" y "borrar" que hay en la segunda estrofa del poema "Hacia tan lejos" y en "Introducción en mi tema" ${ }^{24}$.

Entonces cabe preguntarse cuál es el tema que se "introduce" en el poema inicial "Introducción en mi tema". Pienso que por el hecho de que Isla de Pascua ya ha sido vivida por el hablante, el retomar un poema - "Hacia tan lejos”- concebido con un ánimo tan dispar al que se percibe en La rosa separada e incluirlo bajo el título de "Introducción en mi tema" con las variaciones que hemos visto, apunta hacia lecturas disímiles. Estas lecturas se refuerzan al analizar cómo el uso del tiempo futuro funciona como una irónica evidencia del descalabro ecológico que una turba de turistas representa en el supuesto último lugar incontaminado del planeta. Si en "La isla XXIII" el futuro está siendo usado como irónica demostración de la muerte de la Isla; "Introducción en mi tema", en la lectura que aquí he ofrecido, funciona como una irónica muestra de cómo se ha gastado el símbolo literario de la isla que tan fielmente arraigado tenía el poeta que escribe "Hacia tan lejos" en Geografía infructuosa. La analogía -en términos de Paz- que lo funda supone una reconciliación con la tradición y una confianza en el ordenamiento del mundo. La isla representa en este poema una manera de volver habitable el mundo, pues es el contrario necesario, cumple la fun-

${ }^{24}$ Uno de los múltiples cambios que hay en el poema "Hacia tan lejos" e "Introducción en mi tema” es el tiempo verbal de los versos 7 y 8: en el primero aparece "hasta que el mar lo borre/ y yo salga otra vez_a regresar", en cambio en el segundo dice "hasta que el mar lo borra y yo salgo otra vez, a regresar". Estas variaciones las entiendo como una evidencia de un sujeto que ya no habla desde una idealización, sino que desde una realización de los planes de viaje que tenía, pues se intuye una acción ya realizada. 
ción de contrapunto -como lo dice Elizabeth Frenzel- ante la opresión de la urbe en el imaginario poético nerudiano. La isla, en este poema, es la medida de salvación, la dosis necesaria de esperanza que hace al mundo habitable. Sin embargo, "Introducción en mi tema" muestra esa "herida por la que se desangra la analogía" (Paz, 2008: 81), ese quiebre del principio de identidad que suponía la referencia cultural consagrada que significa el símbolo de la isla heredado de la tradición literaria. El "yo regreso" hacia la Isla, a recuperarme, a recomenzar, a limpiarme, ya no es posible. Solo el regreso contrario lo es, el dejar atrás "la última pureza" ("Los hombres XIX"), si es que acaso todavía existe, para volver a la disonancia que la conciencia de la muerte significa para el sujeto enfermo que sabe que ya no es posible la salvación.

\section{Desmitificación de la isla: El regreso al jardín}

A través de las páginas de La rosa separada se percibe un enjuiciamiento a la vida cotidiana del burgués agobiado, mostrando esta vida de todos los días como una degradación de algo más digno. La descripción de la existencia del pequeño burgués metropolitano recuerda que "Neruda no fue poeta de ciudades. Ellas le inspiran un instintivo rechazo" (Sicard, 2010: xi) ${ }^{25}$. Este desagrado es explicado por José Varela (1992) como un mal que no está en el hombre como ente abstracto, ni tampoco en su morada, sino en su ordenamiento social, en el cual se habría olvidado un modelo de existencia más plena que tal vez se logró en el pasado en algún momento y ahora se asume como un ideal proyectado hacia el futuro. En este olvido radica la culpa del hombre que se expone en algunos poemas, culpa surgida ante una pasividad que permite la perpetuación del sistema ${ }^{26}$. En palabras de Varela, "en algún momento y en algún lugar el hombre debió de vivir de una manera menos miserable, y mientras guarde el recuerdo atávico de ello,

\footnotetext{
${ }^{25}$ La cita completa termina indicando las conocidas excepciones: "Valparaíso, por ser puerto, París por su mercado de las pulgas, Madrid por ser la "ciudad perdida".

${ }^{26}$ Este sentimiento de culpabilidad no es nuevo, Hernán Loyola dice que viene desde "España en el corazón" en "la figura incómoda del culpable por complicidad" (2002: 979).
} 
buscará esa especie de paraíso perdido" (1992: 197). Dos aspectos llaman la atención en esta respuesta. En primer lugar, lo que denomina un "recuerdo atávico", esto es, sentir una conexión con formas de vida más plena que ya no es posible encontrar. Y en segundo lugar, la búsqueda que este recuerdo propiciará de un "paraíso perdido". Una oscura memoria permanece como recuerdo de que el hombre tiene un destino superior, de que puede volver a alcanzar esa existencia más plena que algún día vivió, y que aquello solo podría conjugarse en un paraíso, ahora perdido. La búsqueda de un paraíso perdido, de una edad de oro, de un tiempo pasado mejor, está latente en las ideas que he propuesto hasta ahora. Neruda -es mi hipótesis- va a Isla de Pascua como signo de un "espacio de oro": "isla secreta, rosa/ de purificación, ombligo de oro" dice en "La isla XXIV". La idea de la isla en tanto inicio del mundo, huevo cósmico, origen primigenio ${ }^{27}$, ronda su imaginario y motiva su visita. Sin embargo, una vez allí, la desmitificación -llamémosle- de vertiente parriana lo sacude, la evidencia de la catástrofe, de la "invasión inútil" como dice en el mismo poema "La isla XXIV". La rosa separada representa el último esfuerzo de esperanza utópica, demuestra el anhelo motriz que significa el mito de la Edad de Oro en la creación poética nerudiana. Sin embargo, también representa un conflictivo encuentro entre tradiciones poéticas, el cruce irreconciliable entre el mito y la desmitificación absoluta.

La migración del campo a la ciudad hizo que las personas se amontonaran en las grandes urbes, incorporándose al espacio del progreso. Sin embargo, este cambio conlleva, como su contraparte, la nostalgia o la conciencia del desarraigo: "La nostalgia dora los recuerdos y los sacraliza: el lugar abandonado se reconstruye como morada, como lar, como un oikos perdido, y el arte brota con el propósito, consciente o inconsciente, de ocuparse de la pérdida, llorándola, recordándola o reconstituyendo su espacio imaginario" (Binns, 2004: 23). Esta constante desazón ante un paraíso perdido es ejemplificada por Raymond Williams en El campo y la ciudad (2001), donde utiliza la metáfora de la cinta transportadora para mostrar cómo las actuales generaciones siempre están mirando hacia atrás añoran-

${ }^{27}$ Blumenberg (2004: 371) desarrolla la idea de la isla como "representación ejemplar de lo originario" y Deleuze (2005: 20) la concibe "huevo cósmico", "lugar circular y sagrado donde el mundo vuelve a empezar". 
do tiempos pasados, pensando que si la felicidad de verdad es posible, ésta solo es imaginable en un tiempo anterior. Antes, siempre antes, como si ese antes no tuviera nunca una detención. Mirar siempre hacia el pasado es el ejercicio que se acostumbra a realizar en el medio "civilizado" de la gran ciudad. Corresponde a la forma en que los habitantes intentan redimir y redimirse ante los embates de un progreso que se hace cada día inexorable. ¿Cuándo deberá la cinta detenerse?, Williams se responde, tal vez en el Edén. En el caso de La rosa separada, mi hipótesis sostiene que precisamente Isla de Pascua funciona -en el imaginario común occidental continental- como un arquetipo del Edén, del espacio primigenio de abundancia, pureza y felicidad. Siguiendo estas ideas, el sujeto va a la Isla en búsqueda de aquel pasado mejor que su condición de habitante urbano le incita a imaginar. Niall Binns (2004) discute, a propósito de esta búsqueda de la Edad de Oro en los tiempos actuales, dos actitudes que se desprenden de la literatura contemporánea. Por un lado está la vertiente antipoética que juega con la desmitificación de este tiempo/espacio pasado mejor. La ironía constituye una respuesta ante esta búsqueda siempre hacia atrás, eliminando cualquier atisbo de ilusión. Citando el poema "Moscas en la mierda" de Nicanor Parra: "porque yo nací y me crié con las moscas / en una casa rodeada de mierda", el crítico subraya el radical corte con los discursos de las raíces y los orígenes de felicidad y pureza, apostando a una poesía del presente y de la aceptación. Por otro lado, Binns recuerda la persistencia en la búsqueda del pasado, en la mitificación de la infancia y en el esfuerzo por reconstruir una Edad/Espacio de Oro. Este es el caso, por ejemplo, de Jorge Teillier, quien al recordar las maravillas vividas en los primeros años recibe las fuerzas necesarias para seguir buscando la belleza en su madurez. En "Los poetas de los lares", Teiller explica esta búsqueda y reintegración en el paisaje perdidas ante una experiencia poética meramente literaria que se distanció del contacto directo del hombre con el mundo ${ }^{28}$. Esta vuelta a la tierra tiene como ímpetu "un rechazo a veces in-

${ }^{28} \mathrm{Si}$ en Canto general aparecieron tres poemas dedicados a Rapa Nui, éstos son producto de una experiencia literaria sazonada con un imaginario insular que permitía feminizar y dominar verbalmente este espacio (2013: 256-277). En cambio tras la experiencia de aquel enero de 1971, Neruda escribe empapado de una realidad que entra a ratos en seria contradicción con sus imágenes previas. 
consciente a las ciudades, estas megápolis que desalojan el mundo natural y van aislando al hombre del seno de su verdadero mundo" (Teiller, 1965: 49). De esta forma, la "nostalgia histórica olvidada por la urbanización o por los procesos históricos subyacentes" (Kim, 2010) permite comprender la búsqueda nerudiana de una isla como resguardo y protección para "los pobres hombres/ que se ganaron la vida y la muerte/ trabajando de manera normal o burotrágica ${ }^{29 "}$ (Los hombres IV").

Hernán Loyola ha dicho que desde la publicación en 1958 de Estravagario, se percibe en Neruda una nueva sensibilidad que él ha denominado "posmoderna" y que alcanza en La rosa separada "una definitiva verificación" (2002: 997) ${ }^{30}$. Este cambio en la escritura se evidencia a través de la dualidad que significa por un lado la búsqueda insular, la confianza en el alter orbis que el imaginario promete y, por otro, la constatación del descalabro, del fin de los espacios sagrados, aislados y libres de la invasión humana. Desde una perspectiva ecológica el regreso de Neruda al "ombligo de oro" ("La isla XXIV") que significa la Isla, esto es, a una Edad/Espacio de Oro, implica recuperar el lazo perdido con la fuente y el origen. Es, por lo tanto, desde este punto de vista que resulta indispensable repensar la dualidad mitificación-desmitificación que ha comentado Niall Binns y que propongo clave en La rosa separada. Isla de Pascua está en 1971 en un estado de crisis, según el sujeto que la recorre en su traje de turista. Ya no caben más visitantes, todo el recorrido se ha convertido en un espectáculo mon-

${ }^{29}$ Este neologismo creado por Neruda refuerza la lectura que aquí ofrezco condensando la burocracia, característica del medio urbano, y la tragedia en una sola expresión.

${ }^{30}$ Para profundizar en este tema el artículo "Neruda moderno/posmoderno" resulta esclarecedor. Loyola (1999) realiza una comparación entre el moderno viajero y el posmoderno turista, concluyendo que es en La rosa separada donde se alcanza la máxima verificación de la perspectiva posmoderna. La fragmentariedad del sujeto, el sentimiento de alienación, la sociedad de consumo, el avance de la técnica y su conflicto con la naturaleza, la contaminación de los espacios sagrados, son algunos de los aspectos que desde una perspectiva ecocrítica es posible vislumbrar y poner en cuestionamiento y revisión. "La visión ecológica del mundo rompe dramáticamente con la idea moderna del ser humano como individuo autónomo y centro del universo" dice Binns (2004: 18). De esta forma, si ya sabemos cómo Loyola advierte el distanciamiento en la poesía última de Neruda de sus anteriores esfuerzos de unidad en autorrepresentaciones unívocas (Yo soy, El Capitán...), una lectura atenta a la visión ecológica permitirá explicar, o al menos redirigir nuestra lectura hacia las causas de este rompimiento del sujeto autónomo y centro del universo. 
tado para las masas continentales burguesas ${ }^{31}$ : "El fatigado, el huérfano/ de las multitudes, el yo,/ el triturado, el de cemento,/ el apátrida de los restauranes repletos,/ el que quería irse lejos, siempre,/ no sabía qué hacer en la isla, quería/ y no quería quedarse o volver" ("Los hombres XVI"). Es por lo anterior que pienso que tal vez el único refugio posible que va quedando para el poeta sea la pequeña isla imaginaria que construye en Jardín de invierno. El espacio íntimo de su casa en Isla Negra asoma como la última esperanza insular ${ }^{32}$. El "ideal vacío" 33 que dejó una isla espectacularizada y turistizable ${ }^{34}$ se logrará aprehender tal vez en la escritura y en el delimitado espacio - podado y ordenado por el hombre- de su propio jardín ${ }^{35}$.

Finalmente, hay una pregunta que aparece en uno de los versos de $L a$ rosa separada y que resulta significativa en esta reflexión: "Y para qué vinimos a la isla?" pregunta el hablante en "La isla VII". Creo que esta interrogante, a pesar de su evidente retoricidad, podría funcionar como una

\footnotetext{
${ }^{31}$ Agreguemos a esto la circunstancia en la cual el propio Neruda visita Isla de Pascua: acompañado por un equipo que filmará su experiencia para un documental que será transmitido en un canal de televisión.

32 "Cuando el ser humano no puede recurrir a la isla para alcanzar lo que él considera la suprema libertad o la felicidad que aspira a gozar en ella -tal como lo presiente- se aísla en la circunstancia, poniendo un límite entre el prójimo y él o bien se aísla mentalmente evadiéndose del contorno idealmente" (Pineda Yáñez, 1995: 9). De aquí también puede surgir un indicio que nos permita entender el traslado de la "isla" hacia la "rosa": una flor -la más simbólica- en el cuidado y delimitado jardín nerudiano.

${ }^{33}$ Expresión de Hugo Friedrich que surge ante la sensación de los poetas de sentirse víctima de la modernidad que pesa "como una excomunión" (1959: 51). Explica que "con un rigor frío y metódico", el poeta recorre "todas las fases que nacen obligadamente de la modernidad: el miedo, la imposibilidad de evasión, la claudicación ante el ideal, ardientemente deseado, pero que constantemente se aleja hacia el vacío" (51). Este ideal buscado pero nunca encontrado funciona perfectamente en $L a$ rosa separada, por ejemplo en los versos de "Los hombres XVI": "el que quería irse lejos, siempre/ no sabía qué hacer en la isla/ quería y no quería quedarse o volver". Esta dualidad que brillantemente es capaz de expresar verbalmente Neruda destaca como un "ideal vacío" de un poeta que añora la isla, pero una vez en ella no la puede soportar.

${ }^{34}$ Neologismo de García Canclini (2007: 139), quien a pesar de referirse a las ciudades promovidas mercantilmente, lo extiendo hacia la promoción de las islas como atractivos espacios de recreación y -en el caso de Isla de Pascua- cultura.

${ }^{35}$ Un jardín supone un recinto cerrado, separado, un espacio interior cultivado por el hombre para su propio deleite. Para profundizar en el jardín como artefacto cultural -y en las asociaciones que se desprenden entre él y la isla- se puede consultar con provecho a Roger (2007), específicamente el capítulo "Del jardín al Land art".
} 
confirmación de la hipótesis central de este trabajo. Isla de Pascua en la poesía de Pablo Neruda se manifiesta en dos etapas separadas por la experiencia del viaje en 1971. Por eso la pregunta me parece fundamental, pues inquiere por el momento bisagra de la representación poética nerudiana, el instante en el que confluyen la expectativa y la experiencia, cuando se ponen en juego las imágenes con la evidencia de la realidad. Es ese el crucial encuentro que me permitió investigar cómo Neruda representa Isla de Pascua en su poesía, su viaje impulsó la pregunta por la representación. "Para qué vinimos a la isla?", significa que se derrumban todas las certezas que antes del viaje permanecían cómodamente instaladas en el archivo, resguardadas por su arconte. "Para qué vinimos a la isla?" implica que la experiencia se enfrenta a la expectativa desarmando sólidas raíces. "Para qué vinimos a la isla?” responde a la fuerza de atracción que la imagen de una pequeña isla en medio del océano proyecta en los hombres urbanos. "Para qué vinimos a la isla?" es en definitiva la triste comprobación de la imposibilidad de alcanzar el ideal insular aspirado por el poeta.

\section{Referencias}

Aínsa, F. (2000). Islario contemporáneo. Espejo de paciencia 5, 9-15. Disponible en http://acceda.ulpgc.es/bitstream/10553/3396/1/0234608_oooo5 _ooo1.pdf

. (2001). Las ínsulas de tierra firme de la narrativa hispanoamericana: Entre la memoria y la esperanza. En C. Alemany Bay, R. Mataix y J. C. Rovira (ed), La isla posible: III Congreso de la Asociación Española de Estudios Literarios Hispanoamericanos (pp. 17-26). Alicante: Universidad de Alicante.

Alonso, M. N.; Blum, A.; Cerda, K.; Cid, J.; Oelker, D.; Sánchez, M.; Triviños, G. y Villavicencio, M. (2005). Donde nadie ha estado todavía: Utopía, retórica, esperanza. Atenea, 491, 29-56.

Araya, J. G. (2006). Ética, política y poética: Hacia una lectura ecocrítica de Pablo Neruda. Revista de Crítica Literaria Latinoamericana, 63/64, 253263.

Binns, N. (2001). Los indicios del fin: La poesía ecologista de José Emilio Pacheco. Literatura y Lingüística, 13, 125-144.

(2004). ¿Callejón sin salida? La crisis ecológica en la poesía hispanoamericana. Zaragoza: Prensas Universidad de Zaragoza.

Blumenberg, H. (2004). Salidas de caverna. Madrid: Antonio Machado. 
Concha, J. (1985). Cruzar en Residencia en la tierra. Revista de Crítica Literaria Latinoamericana, 11, 109-119.

Deleuze, G. (2005). Causas y razones de las islas desiertas. En La isla desierta y otros textos. Textos y entrevistas (1953-1974) (pp. 15-20). Valencia: PreTextos.

Delgado, M. (2000). Trivialidad y trascendencia. Usos sociales y políticos del turismo cultural. En J. Larrosa y C. Skliar (eds.), Habitantes de Babel. Política y poéticas de la diferencia (pp. 244-277). Barcelona: Laertes.

Durand, G. (2006). Estructuras antropológicas del imaginario. Introducción a la arquetipología general. México: Fondo de Cultura Económica.

Fischer, H. (2001). Sombras sobre Rapa Nui. Alegato por un pueblo olvidado. Santiago: Lom.

Frenzel, E. (1980). Diccionario de motivos de la literatura universal. Madrid: Gredos.

Friedrich, H. (1959). Estructura de la lírica moderna. De Baudelaire hasta nuestros días. Barcelona: Seix Barral.

Galilea, M. (2011). Epílogo. En Pablo Neruda. La rosa separada. Tiare Haka Topa He Rosa. Pablo Neruda Rapanui (pp. 108-109). Santiago: Origo. . (2013). Isla de Pascua en la poesía de Pablo Neruda: Idealización y desencanto. Tesis Pontificia Universidad Católica de Valparaíso. En Haz tu tesis en cultura. Santiago, Chile: Consejo Nacional de la Cultura y las Artes. Disponible en http://www.observatoriocultural.gob.cl/haz-tu-tesisen-cultura/203/

. (2015). Isla de Pascua en la poesía de Neruda. A contracorriente, 12 (2), 90-100. Disponible en http://acontracorriente.chass.ncsu.edu/index.php/ acontracorriente/article/view/1062.

Galindo, Ó. (2000). El imaginario insular antiutópico en la poesía chilena reciente. Revista Austral de Ciencias Sociales, 4, 175-185.

García Canclini, N. (2007). Imaginarios urbanos. Buenos Aires: Eudeba.

Hahn, O. (2004). Prólogo. En Geografía infructuosa (pp. 6-13). Buenos Aires: Debolsillo.

Hau' Ofa, E. (1994). Our Sea of Islands. The Contemporary Pacific, 6 (1), 147161.

Jameson, F. (1977). Of islands and trenches: Naturalization and the production of utopian discourse. Diacritics, 7 (2), 2-21. Disponible en http://www. jstor.org/discover/10.2307/465017?uid=3737784\&uid=2129\&uid=2\&uid $=70 \&$ uid $=4 \&$ sid $=21101930716791$.

Jolly, M. (2007). Imagining Oceania: Indigenous and foreign representations of Our Sea of Islands. The Contemporary Pacific, 19 (2), 508-545.

Kim, H. J. (2010). La literatura de Homero Aridjis desde la cosmovisión ecológica. Tesis. Universidad de Chile. Disponible en http://www.tesis.uchile.cl/ tesis/uchile/2010/fi-kim_j/html/index-frames.html. 
Koselleck, R. (1993). Futuro pasado: Para una semántica de los tiempos históricos. Barcelona: Paidós.

Krotz, E. (2004). La otredad cultural entre utopía y ciencia. Un estudio sobre el origen, desarrollo y la reorientación de la antropología. México: Fondo de Cultura Económica.

Loyola, H. (1999). Neruda Moderno/ Neruda Posmoderno. América sin nombre, 1, 21-32.

. (2002). Notas. Tomo III. En Obras Completas. De Arte de pájaros a El mar y las campanas. 1966-1973 (pp. 941-1067). Barcelona: Galaxia Gutenberg/Círculo de Lectores.

Magadish, J. y De Beer, J.-M. (2001). América mágica. Mitos y creencias en tiempos del descubrimiento del nuevo mundo. Santiago: Lom ediciones.

Marcilly, Ch. (1976). La meditación nerudiana sobre Isla de Pascua desde el Canto General hasta La rosa separada. En Coloquio Internacional sobre Pablo Neruda (La obra posterior al Canto General (pp. 157-165). Poitiers: Centre de Recherches Latino-Américaines de l’Université de Poitiers.

Martínez, M. (1998). Islas flotantes. En Las islas extrañas. Espacios de la imagen (pp. 19-46). Las Palmas de Gran Canaria: Tabapress.

- (1999). Las Islas de los Bienaventurados: Historia de un mito en la literatura griega arcaica y clásica. Cuadernos de Filología Clásica, 9, 243-279. Disponible en revistas.ucm.es/index.php/CFCG/article/download/.../31444

. (2010). Islas míticas en relación a Canarias. Cuadernos de Filología Clásica, 2O, 139-158. Disponible en http://revistas.ucm.es/index.php/CFCG/ article/view/CFCG1010110139A

Mistral, G. (2008). Recado sobre las islas. En Gabriela Mistral en Puerto Rico (pp. 95-97). Selección y prólogo de Luis Arrigoitia. San Juan: La Editorial, Universidad de Puerto Rico.

Müller, B. (2011). Edén Patagónico, una lectura del espacio en La espada encendida. Revista Chilena de Literatura, 79, 109-125.

(2011). Mujer y geografía en La espada encendida de Pablo Neruda. Tesis. Universidad de Chile. Disponible en http://www.tesis.uchile.cl/tesis/ uchile/2011/fi-muller_b/html/index-frames.html

Neruda, Pablo. (1997). La rosa separada. Santiago: Losada. . (1999-2002). Obras Completas. Cinco volúmenes. Edición y notas de Hernán Loyola. Barcelona: Galaxia Gutenberg/Círculo de Lectores. . (2004). Geografía infructuosa. Barcelona: Debolsillo.

Nouzeilles, G. (2002). Introducción. En G. Nouzeilles (comp.), La naturaleza en disputa. Retóricas del cuerpo y el paisaje en América Latina (pp. 1038). Buenos Aires: Paidós.

Oses, D. (1999). Pablo Neruda y Rapa Nui. La isla imposible. Disponible en http://www.nuestro.cl/chilecronico/neruda_rapa_nui1.htm 
Ostria, M. (2002). Poesía y oralidad. Acta Literaria, 27, 67-75. . (2004). Visión nerudiana del desierto nortino. Revista Chilena de Literatura, 65, 111-121.

. (2010). Notas sobre ecocrítica y poesía chilena. Atenea, 502, 181-191.

Paz, O. (2008). Los hijos del limo. Del romanticismo a la vanguardia. Santiago: Tajamar Editores.

Pineda Yáñez, R. (1955). La isla y Colón. Buenos Aires: Emecé.

Pizarro, A. (2009). Amazonía. El río tiene voces. México: Fondo de Cultura Económica.

Rivero, E. (1976). Análisis de perspectiva y significación en La rosa separada de Pablo Neruda. Revista Iberoamericana, 96-97, 459-472.

Rodríguez, I. (2002). Banana Republics: Feminización de las naciones en frutas. En G. Nouzeilles (comp.), La naturaleza en disputa. Retóricas del cuerpo y el paisaje en América Latina (pp. 85-112). Buenos Aires: Paidós.

Rodríguez, O. (1986). Introducción a la poética de Pablo Neruda. Tesis. Universidad Complutense de Madrid.

. (1995). La poesía póstuma de Pablo Neruda. Maryland: Ediciones Hispamérica.

. (2004). La poesía póstuma de Pablo Neruda: Viaje al interior de sí mismo. En Neruda en su Centenario (pp. 177-206). Sevilla: Universidad de Sevilla y Fundación El Monte.

- (2012). El motivo del viaje en la poesía póstuma de Pablo Neruda. En Ecos y estelas de un maestro: Homenaje a Mauricio Ostria González (pp. 185-202). Concepción: Cosmigonon.

Roger, A. (2007). Breve tratado del paisaje. Madrid: Biblioteca Nueva.

Rojas, M. (1981). Configuración mítica de La rosa separada de Pablo Neruda. Texto crítico, 22-23, 163-193.

Sáinz de Medrano, L. (2001). Las islas de Neruda. En C. Alemany Bay, R. Mataix y J. C. Rovira (eds.), La isla posible: III Congreso de la Asociación Española de Estudios Literarios Hispanoamericanos (pp. 565-575). Alicante: Universidad de Alicante.

Salazar, N. (2006). Antropología del turismo en países en desarrollo: Análisis crítico de las culturas, poderes e identidades generados por el turismo. $\mathrm{Ta}$ bula Rasa, 5, 99-128.

Sicard, A. (2010). Entre lo inhabitado y la fraternidad. En H. Loyola (ed.), Antología general (pp. xxix-liv). Santiago: Alfaguara. Real Academia Española. Edición Conmemorativa.

Teillier, J. (1965). Los poetas de los lares. Nueva visión de la realidad en la poesía chilena. Boletín de la Universidad de Chile, 65, 48-62. Disponible en http://www.memoriachilena.cl/archivos2/pdfs/MCo011182.pdf

Teitelboim, V. (1984). Neruda. Madrid: Ediciones Michay. 
Tomé, Mario. (1987). La Isla: Utopía, inconsciente y aventura: Hermenéutica simbólica de un tema literario. León: Universidad de León.

Varela, J. (1992). El tema de la alienación en La rosa separada de Pablo Neruda. Revista Canadiense de Estudios Hispánicos, 1, 177-206.

White, S. (2006). Los ríos en la poesía chilena: Nuevas definiciones ecocéntricas de la poesía épica y lírica. Crítica Hispánica, 28 (1), 125-152.

Williams, R. (2001). El campo y la ciudad. Buenos Aires: Paidós.

Young, F. (2012). 'I he Koe? Placing Rapa Nui. The Contemporary Pacific, 24 (1), 1-30. 